\title{
Ahí donde el historiador olvida, el novelista recuerda: lectura hermenéutica de Poderes secretos, de Miguel Gutiérrez
}

\section{Where the historian forgets, the novelist recalls: A hermeneutic reading of Miguel Gutierrez's Poderes secretos}

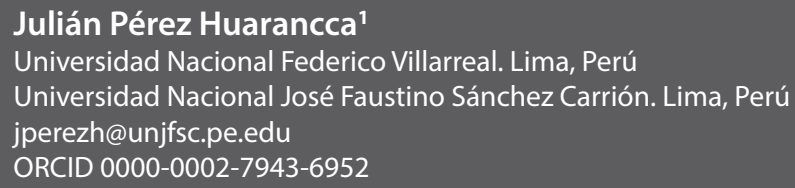

Citar como: Pérez Huarancca, J. (2019). Ahí donde el historiador olvida, el novelista recuerda: lectura hermenéutica de Poderes secretos, de Miguel Gutiérrez. Desde el Sur, 11(2), pp. 169-182.

\section{RESUMEN}

Con un título que repite un breve extracto de la novela Poderes secretos, pretendemos expresar algunas reflexiones sobre la performance del discurso narrativo literario en el intento de simbolizar lo Real, que siempre retorna en las relaciones humanas. De igual manera, queremos establecer algunas ideas sobre las formas de como el discurso artístico trabaja en favor de la memoria y se constituye a veces en una designación de una verdad y se convierte en una muestra de fidelidad a esa verdad.

\section{PALABRAS CLAVE}

Poder, memoria, olvido, novela, historia, hegemonía, subalternidad, simbólico, real, verdad.

1 Julián I. Pérez Huarancca es doctor en Literatura Peruana y Latinoamericana por la Universidad Nacional Mayor de San Marcos y magíster en Literatura Hispanoamericana por la Pontificia Universidad Católica del Perú. Docente de Literatura en las universidades nacionales Federico Villarreal y José Faustino Sánchez Carrión. Ha publicado diversos estudios en revistas propias de la especialidad. Es tres veces premio nacional como novelista: Premio Federico Villarreal por Retablo (2003), Premio Copé Oro por Criba (2013) y Premio de Novela Breve Julio Ramón Ribeyro por Anamorfosis (2017). Formó parte de la delegación peruana a la FILBO de Bogotá 2014. 


\section{ABSTRACT}

With a title that repeats a brief extract from the novel Poderes secretos, our aim is to offer a reflection upon the success of literary narrative discourse in its attempt to symbolize the Real, while returning always to human relations. At the same time, we seek to address ideas concerning the ways in which artistic discourse contributes to memory and can in some cases find itself functioning as a truth and as a testament to the fidelity of that truth.

\section{KEYWORDS}

Power, memory, forgetting, novel, history, hegemony, subalternity, symbolic, real, truth.

\section{Introducción}

En nuestra consideración, Miguel Gutiérrez es de los escritores que trabajan, más que cualquier otro en el ámbito de la narrativa peruana, con las ideas en sus obras y no solo con las puras opiniones, como materia prima de su narrativa. En otras palabras, es de los escritores peruanos que, al escribir sus textos, lo que hace también es descorrer las pantallas fantasmáticas tras de las cuales se encuentran, por ejemplo, los trágicos desencuentros en las relaciones humanas, sus causas y motivaciones. Por eso mismo, creemos entender, la lectura de sus obras no solo es placentera, sino que provoca otras emociones más fuertes, un goce, como rabia, amargura, miedo, estupor, de forma tal que ciertos lectores contingentes y superficiales prefieren desdeñarlas. Es que el horror de lo real quema, abrasa, desafía, emplaza, en suma: es insoportable.

No descubrimos nada nuevo si afirmamos que la novela en alusión desarrolla el tema de las relaciones de poder y cultura en un mundo posible, con lo que pone en escena de manera implícita las conexiones de poder y cultura en la sociedad peruana. Es que, más allá de la evidencia y la contingencia de estas realidades imaginadas, lo que asoma es la problemática actual de las relaciones culturales en el Perú. Gracias a las posibilidades envolventes y el discurso ambiguo propio de la novela, Poderes secretos nomina al mismo tiempo dos cosas: el mundo imaginado, pero subrepticiamente se refiere además al mundo real y/o plantea un asedio a lo Real.

\section{I}

Partamos del título de este trabajo. Hay una realidad real, hay dos tipos de discurso (el del historiador y el del novelista); además, está la afirmación del olvido. ¿Quién olvida qué? ¿Es un olvido consciente o inconsciente? ¿Por qué la necesidad de evidenciar ese olvido? ¿Cómo recupera la 
memoria de lo olvidado el discurso novelístico? Aquí hay varias preguntas establecidas a partir del enunciado que se constituye en el título de este texto.

Empecemos por conceptualizar, aunque sea muy brevemente, la realidad. No es tan fácil definirla. E. Kant sostiene que la realidad no existe. La hace existir nuestro pensamiento puesto en acción, que vendría a ser el lenguaje. Mucho antes de conocer el trabajo sistemático del filósofo francés Alain Badiou, parecían tan convincentes las tesis materialistas y no queríamos aceptar algo evidente: que, en efecto, a Kant no le faltaba razón en lo sustancial. Pero siguiendo las pautas de Badiou, no hay mucho que discutir en aceptar la enseñanza de Kant a este respecto. Cuando Badiou distingue entre el Ser en tanto ser y el Ser ahí o entre lo múltiple puro del múltiple contabilizado, está diciendo casi lo mismo. Solo que la argumentación de este último es más basta, compleja y categórica.

Pues bien, entonces qué es para nosotros la realidad. Sin la pretensión de establecer afirmaciones acabadas, podríamos decir que la realidad es aquello que el lenguaje delimita, nomina o simboliza en todo lo que es la multiplicidad infinita del Ser en tanto ser. El lenguaje, pues, esencialmente nomina, categoriza y clasifica las cosas y los fenómenos. Pero más allá de lo abarcado por el lenguaje, siempre queda un resto o una realidad pura que no entra en su contabilidad. Jacques Lacan sostiene que ese aquello que no entra en la contabilidad del lenguaje se llama precisamente lo Real. Y lo Real es lo más basto, lo más inconmensurable o, en sentido contrario, lo menos basto y lo menos mensurable y que la realidad no es sino una construcción simbólica, por tanto efímera y contingente. De donde es posible concluir que el lenguaje no lo abarca todo. Esto es fundamental comprenderlo.

Vamos con el segundo punto, según su importancia para el interés de este trabajo. Se trata del olvido. ¿Qué es olvidar? La Real Academia Española (RAE) afirma que olvidar es: «1. Cesación de la memoria que se tenía, 2. Cesación del afecto que se tenía y 3. Descuido de algo que se debía tener presente». Solo las definiciones 1 y 3 parecen estar involucradas en lo que se refiere a las ideas que se discuten en este trabajo. Desde luego, la definición de la RAE sobre el olvido o sobre olvidar solo es un parámetro previo y elusivo. En su libro La memoria, la historia, el olvido, Paul Ricoeur ${ }^{2}$ tematiza el concepto de olvido en un libro fundamental y tan extenso, de

2 Paul Ricoeur (1913-2005) fue un filósofo y antropólogo francés que, desde la perspectiva de la fenomenología y de la hermenéutica, escribió muchos libros. Lo que particularmente nos interesa en el desarrollo de nuestro trabajo es la discusión que plantea acerca de la memoria, el deber de la memoria y la memoria cultural en Memoria, historia, olvido (2000). 
cuya lectura nos queda la idea de que no se puede hablar de olvido sin relacionarla con la palabra o el enunciado memoria. Para lo que nos interesa en este trabajo, los enunciados olvido y recuerdo son fundamentales. Pero lo último es mejor relacionarlo con memoria, en el sentido que le da a esta palabra Ricoeur, para relacionarlas con la historia, como discurso que da cuenta de la memoria que, por otro lado, puede ser objeto de manipulación y borramiento. Incluso puede ser alterado por una narrativa de la memoria establecida desde la dominación. En un momento inicial de su investigación, Ricoeur dice:

A la memoria se vincula una ambición, una pretensión, la de ser fiel al pasado; a este respecto, las deficiencias propias del olvido, que evocaremos con amplitud en su momento, no deben tratarse de entrada como formas patológicas, como disfunciones, sino como el reverso de sombra de la región ilustrada de la memoria (Ricoeur, 2003, p. 81).

Al mencionar el reverso de sombra de la región ilustrada de la memoria, lo que especifica Ricoeur es precisamente la intromisión del inconsciente en las supuestas narrativas que se presupone conscientes sobre la historia o tema de historia.

Más adelante este estudioso aclarará que la memoria se relaciona con el recuerdo (recuerdos) enmarcándolo o subsumiéndolo; es decir, la memoria está hecha de recuerdos y es del pasado. Pero es claro que la opone a la idea de olvido en la misma dimensión significativa. Desde ya, debemos plantear que lo que nos interesa de este extenso libro de Ricoeur son, estrictamente hablando, el punto 2 de la primera parte («De la memoria y de la reminiscencia») y el punto 3 de la tercera parte («La condición histórica»), porque se relacionan con proximidad a los intereses del presente trabajo.

Pues bien, la afirmación «ahí donde el historiador olvida, el novelista recuerda», para ser comprendida en la orientación que argumentamos, tiene que merecer algunas restricciones y explicaciones. En realidad, se trata de un enunciado de hondas repercusiones. ¿Qué olvida el historiador, cómo así, para qué y por qué? En primer lugar, conviene enfatizar que historiador es quien escribe o estructura la narrativa de la historia de hechos o fenómenos sociales ocurridos. De hecho, entonces, el enunciado se refiere a la historia, al discurso o a la narrativa producida por el historiador. Quien olvida o recuerda es el historiador. $Y$ ese recuerdo o ese olvido queda evidenciado en el discurso que él forja a través de la escritura o del lenguaje en general. El olvido o la memoria del historiador puede fácilmente desdoblarse en dos tipos: el consciente y el inconsciente, puesto que el discurso también lo es así por naturaleza. En todo caso, lo 
que nos importa aquí es el olvido consciente que conlleva los efectos de las relaciones de poder y que está afectado por el mismo hecho de que los significados dependen también del lugar desde donde se articula el texto, sea historiográfico o de otra naturaleza, en los cuales está inserto el individuo y, desde luego, sus intenciones. A este olvido es que, según nuestra observación, Gutiérrez se refiere en el enunciado que tomamos de su libro Poderes secretos.

Es decir, al olvido que el historiador comete exprofeso, como individuo que forma parte de una parcela humana, sobre todo como letrado miembro de un grupo esencialmente dominante. No es un descubrimiento que la narrativa de la predominante historia oficial del Perú siempre fue forjada por los letrados criollos. Esta narrativa, pues, está plagada de olvido y escamoteo. Olvido y escamoteo que abona en favor de los intereses de los grupos hegemónicos y que afecta a lo grupos emergentes y residuales. Este olvido, entonces, forma parte, es un resto que no cesa de insistir, de la memoria establecida por la historia oficial como discurso y como narrativa sobre el devenir de la nación peruana. Es a esto que se refiere Ricoeur en el siguiente extracto:

La dominación, como hemos visto, no se limita a la coacción física. Hasta el tirano necesita un retórico, un sofista, para proporcionar un intermediario a su empresa de seducción y de intimidación. El relato impuesto se convierte así en el instrumento privilegiado de esta doble operación [...] De este modo, se hace posible vincular los abusos expresos de la memoria a los efectos de distorsión propios del plano del fenómeno de la ideología. En este plano aparente la memoria impuesta está equipada por una historia «autorizada», la historia oficial, la historia aprendida y celebrada públicamente (pp. 116-117).

Por otro lado, como ya lo dijimos, es cierto que ningún discurso captura lo real. No lo hace tampoco el discurso literario, el discurso novelístico incluido, toda vez que pertenece a lo que Lacan denomina «orden simbólico». Sin embargo, es precisamente en este punto que el discurso novelístico, por pertenecer al terreno del arte, toma una visible ventaja con respecto al discurso historiográfico en esto de ser más fiel o más próximo a lo real. Por lo tanto, se confirma lo que sostiene Gutiérrez: Ahí donde el historiador olvida, el novelista recuerda. En otras palabras, la memoria forjada por el novelista tiene mayor espesor y densidad en cuanto a su aproximación a lo Real. Pero hace falta también una fundamentación un poco más detallada para que esta afirmación sea convincente.

Massimo Recalcatti (2012), el exégeta italiano de Lacan, puntualiza que, en los estudios psicoanalíticos lacanianos, se visualiza que hay tres definiciones sobre el arte en cuanto discurso que bordea lo Real y que 
pugna por simbolizarlo, más que ninguna otra elaboración simbólica ${ }^{3}$. Recalcatti afirma:

La tesis lacaniana de la obra de arte como borde del vacío de das Ding nos incita a preservar, por el contrario, una distancia esencial entre la obra de arte y el vacío que esta organiza y circunscribe [...], para Lacan el arte es una circunscripción significante de la incandescencia de la Cosa [...] El ser de la Cosa freudiana, retomada por Lacan, no es solo (heideggerianamente) aquello que marca el límite de la representación. Es, si se quiere, el carácter hermenéutico de la Cosa, su excentricidad irreductible con respecto a las imágenes y al significante [...], es más bien un vacío que deviene vórtice, «zona de incandescencia», abismo que aspira, exceso de goce, horror, caos terrorífico (p. 13).

Precisamente, en esto de simbolizar lo real que resulta la memoria toda y fiel de lo acontecido (pero no solo en eso sino en todo lo que ficcionaliza) el arte realiza tres performances: a) se aproxima y aleja sobre la región incandescente de lo Real y en ese acercarse y alejarse nos proporciona una idea de eso que quema y que cualquier otro discurso no puede simbolizarlo; b) el arte construye un campo de visones anamórficos de lo real, que aun cuando no puede capturarlo, nos lo insinúa para una mirada al sesgo; y c) a través del lenguaje del arte se puede insinuar que lo real se inscribe en nosotros y nos captura como una marca y habla a través de todo lo que podamos simbolizar. Dicho sea de paso, esto último es bastante complejo para explicar en pocas palabras. Lo difícil que resulta alguna explicación clara, al respecto, lo apunta el propio Recalcatti. De todo lo antes dicho, empero, lo que queda claro es la ventaja que tiene el discurso artístico (de hecho, que se incluye el discurso novelístico) sobre el discurso historiográfico o cualquier otro en la elaboración de la memoria. Por esto mismo, resulta contundente la afirmación de Gutiérrez en Poderes secretos, aquello de que el novelista es un historiador privilegiado.

Sin embargo, Gutiérrez no solo problematiza y puntualiza la mayor densidad y espesor del discurso novelístico en cuanto artefacto cultural que preserva la memoria, sino además hace visible otra cuestión de honda repercusión: el tratamiento del poder que manipula la memoria. En este punto resulta útil recordar que el filósofo esloveno S. Žižek (2001) cuestiona a Foucault por eso de la microfísica del poder y su tesis de que el poder está diseminado y que casi tiene vida propia. El esloveno sostiene

3 Massimo Recalcati (1959) es un filósofo italiano de vasto trabajo basado en el psicoanálisis lacaniano. En este trabajo nos interesa particularmente la propuesta desarrollada por él en su libro Las tres estéticas de Lacan. 
que el poder que se impone y por tanto se visibiliza es el hegemónico. A este poder es que se refiere Gutiérrez con el enunciado «poderes secretos»; es decir, no a un poder cualquiera, sino al poder que proviene de la esfera de la dominación. En otras palabras, poderes que operan tras una serie de pantallas fantasmáticas elaboradas e impuestas por la hegemonía de manera implícita más que explícita. Es verdad, la emergencia y lo residual también expresan o constituyen un poder por muy oculto y débil que fuesen, pero es el poder hegemónico que en definitiva quien pinta todo el escenario de las relaciones humanas con sus colores.

II

Una pregunta que cae por su propio peso, como consecuencia de lo antes dicho, es la siguiente: ¿Es que el discurso elaborado por todos los artistas garantiza la exposición de lo Real o por lo menos la mayor exposición de lo real? La respuesta sería por un lado sí y por otro, no. Sería sí en la medida en que consideramos el privilegio de la escritura artística según las ideas de Lacan sobre el discurso artístico. Sería no, si consideramos y tomamos en cuenta la recomendación de Jacques Rancière ${ }^{4}$ con respecto al giro estético de la ética y de la política que se han operativizado en el mundo contemporáneo. Este filósofo posmarxista francés afirma enfáticamente que en el mundo contemporáneo se ha establecido, en efecto, un giro ético de la estética y de la política; esto desde luego desde la perspectiva e intereses de la hegemonía mundial.

Rancière (2015), refiriéndose a la estética específicamente, ha formulado la tesis de que la hegemonía ha establecido una nueva forma de realizar el reparto de lo sensible; de tal modo que, en la agenda de todo tema a tratarse sobre las relaciones sociales y culturales, lo que se privilegia es lo que ella, la hegemonía, determina. En el mundo contemporáneo la agenda está orientada al tratamiento del ser humano como una víctima. Fundamentalmente como víctima del «terrorismo». Este es el punto central. De forma tal que, en nombre de la «democracia», todos los discursos culturales tienen libertad de tratar este tema, pero desde la perspectiva establecida por la hegemonía. Pero por supuesto que hay otros temas en la agenda de la hegemonía mundial; sin embargo, esos también tienen que orientarse de acuerdo a lo que subrepticiamente reglamenta el nuevo reparto de lo sensible. Desde luego que Rancière, después de plantear tan esclarecedores conceptos, postula la urgente necesidad de un arte orientado a combatir ese nuevo reparto operado en la esfera de lo numerosos trabajos. De él nos interesa su libro El giro ético de la estética y de la política. 
sensible; por lo que todo arte debe tener un cariz antiimperial. No podemos pormenorizar las ideas fundamentales de Rancière en este trabajo, pero sí tomarlo en cuenta para formular la propuesta de que no tiene pues, la misma importancia toda la producción literaria que se refiere a la recuperación de la memoria, sino que hay segmentos que abonan más bien en el olvido. Ya sea tratándolo desde una perspectiva estratégica de las puras opiniones, mas no así desde la disposición del nombramiento de una verdad o eligiendo temas tan circunstanciales y contingentes, como por ejemplo lo que prefiere la cultura de la queja, la narrativa de la mismidad o los libros de éxito o simplemente exitosos. Pero esta elaboración discursiva requiere de algunas precisiones.

En efecto, también desde la perspectiva del posmarxismo, un pensador tan lúcido como Alain Badiou, ha puesto sobre el tapete la problemática de la verdad en función de los procesos acontecimientales. El acontecimiento es el proceso que pone de manifiesto, sobre todo de manera fugaz, como el deslumbramiento fugaz que provoca un relámpago, la verdad. De modo que siendo el arte un sitio de verdad, puede ser tributaria de verdad solo en la medida en que se orienta en la dirección del acontecimiento. Esto es clave enfatizarlo, debido a que últimamente hay críticos, desde la perspectiva del puro saber, que se apuran en considerar como acontecimiento casi cualquier alboroto, cualquier arte hecho para turistas culturales. Para poner un ejemplo: la poesía de Vallejo, sobre todo la de su última etapa, es una poesía de encuentro con la verdad, con lo que Badiou llama la Idea. En el caso de Vallejo, es una poesía de encuentro con la idea comunista, es el sostén de la hipótesis sobre un mundo nuevo por venir. Solo en esa medida es un arte de acontecimiento, puesto que nombra una verdad. Para Badiou no cualquier movimiento o proceso es un acontecimiento. Incluso bordeando un acontecimiento, las obras de arte a veces no pueden considerarse que sostienen una verdad, porque pueden más bien representar lo oscuro o lo reactivo o, simplemente, abundan en el mundo del saber, pero no de la verdad. Llevemos esto a la definición de la memoria, al sostenimiento de la memoria y por lo tanto a rechazar el olvido que enarbola el discurso dominante, ya sea historiográfico o sea artístico. El trabajo de la memoria es más bien el sostenimiento de una verdad que ocurrió en algún momento del pasado y que exige su designación porque precisamente hay discursos o pantallas fantasmáticas que la niegan, que la oscurecen porque es incómodo, porque no deja de perturbar. Particularmente, se nos ocurre pensar que el discurso novelístico de Gutiérrez es uno que se mantiene fiel a la memoria que sostiene una verdad. Pero una verdad es un guarismo que se encuentra de modo natural en el conjunto vacío; es decir, siguiendo la enseñanza de Lacan, es lo real que no puede simbolizarse y que permanentemente retorna. 
Pero cuál sería esa verdad que el discurso novelístico, según la afirmación de Miguel Gutiérrez, no olvida. Aunque no lo diga expresamente, lo que el enunciado afirma es que hay asuntos, realidades, sucesos, personajes, del pasado que han sido borrados o desfigurados en el discurso historiográfico hegemónico. Aquellos que son incómodos o que desestabilizan al discurso y a la posición dominante, aquellos que por eso mismo no entran en su contabilidad y forman parte del olvido, pero que no por eso cesan de insistir por entrar en la cuenta de la memoria, que, al contrario, exigen su redención. Refiriéndose a esto mismo el filósofo italiano Giorgio Agamben dice que la memoria escamoteada no se diluye ni se esfuma, con el tiempo siempre encuentra de qué manera reaparecer, muy al margen de quienes lo quieran o no. Pero Gutiérrez no solo problematiza eso, sino que tematiza la idea de cómo se construye a partir del olvido y del archivo reconstruido de la figura de un ícono, no solo a gusto, sino para hacerlo funcional a los intereses culturales y de poder de la dominación. Cuando en el horizonte fictivo de la novela Poderes secretos pone en tela de juicio la autoría de Garcilaso con respecto a Comentarios reales, lo que busca es hacernos pensar más allá de lo conocido y reconocido secularmente, de lo aparentemente cierto, de lo externamente tangible; de hacernos reflexionar en el espacio de los significados indeterminados para armar un nuevo texto que desestabilice lo que antes creíamos como definitivo. Dicho de otra forma, lo que sugiere Gutiérrez con poner a Garcilaso en la posición de un autor falaz, de un intelectual usado por los jesuitas a cambio de alguna fama, no es precisamente cuestionar a un autor sino al emblema cultural que la dominación prohispana y sus herederos han hecho del Inca Garcilaso.

Dicho de manera más simple, lo que hace la historia oficial es construir o reconstruir la imagen de los intelectuales y a los personajes de la historia como artefactos culturales hechos a imagen y semejanza de sus intereses. No podría ser de otro modo. Si no cómo puede pensarse en cómo se recicla año tras año, siglo tras siglo, la dominación; cómo puede aceptarse y asumirse que el mundo de injusticias, estropicios sociales, un verdadero basurero de corrupción y de privilegio de lo circunstante y contingente es posible y viable. Como es que seres humanos con un avance tecnológico nunca antes visto no sean capaces de orientarse hacia el logro de unas relaciones mínimamente humanas en todo el mundo. Como diría Gabriel García Márquez, ese mundo de relaciones realmente humanas aún está por inventarse; esto no solo es metafórico, sino, más bien, puramente lógico. Nos parece que es esta la verdad que Gutiérrez trata de sostener, como tal, con la afirmación que aparece en el enunciado que va como una parte del título de este artículo. Hay quienes, sin embargo, asumen que el 
borramiento de la memoria y su consiguiente reemplazo por una narrativa falaz solo se da en las dictaduras. Esto, desde luego, es una afirmación equivocada. La idea de que hay épocas democráticas donde no se intenta aquello es ciertamente hasta un bello cuento folclórico.

En alguna entrevista dijimos, por nuestra parte, que la lectura y la escritura literaria, sobre todo la novelística, no es meramente un placer, sino también implica dolor; por tanto, es un goce. Muy aparte de esto, podemos señalar que la práctica artística de Gutiérrez siempre ha sido un combate. Un combate por exponer ideas antes que meras opiniones sobre cualquier tema elegido, tanto en sus obras novelísticas como también en sus estupendos ensayos. Para los lectores contingentes leer los textos de Gutiérrez debe ser como agarrar una brasa, una brasa ardiente para hacer más específica la alusión. En el enunciado que motiva estas líneas hay una indicación de esto. El combate del novelista es por privilegiar la memoria y eso queda dicho. ¿Pero por qué privilegiar la memoria? ¿Qué tipo de memoria y para qué?

Volvamos a la pregunta qué verdad es lo que sostiene Gutiérrez en el enunciado que estamos tratando de dilucidar. La respuesta no puede ser otra sino la verdad de la memoria olvidada, ex profeso, como producto de las relaciones de poder de un universo humano desgraciadamente escindido y jerarquizado. Bien puede agregarse a ello que Gutiérrez problematiza y sostiene la verdad que se agita en la memoria colectiva de los sectores sociales y culturales emergentes y residuales. A ese resto que no se simboliza y que sencillamente no puede ser simbolizada en el discurso hegemónico sobre la historia del Perú.

En una de las inquietantes propuestas de la estudiosa hindú Gayatri Spivak ${ }^{5}$, se afirma que el sujeto subalterno no tiene voz. A esto se puede agregar que tampoco tiene memoria. Aunque tenga una memoria en lo Real del tiempo transcurrido, no tendrá voz ni memoria nominada y aceptada en tanto no haya instituciones que la reconozcan. En el mundo contemporáneo, con el giro ético de la política y de la estética, esto se apuntala con mayor rigor y exigencia. Tratar la memoria del pasado, como lo hace Gutiérrez en sus obras, es precisamente nombrar una verdad, sostener una verdad que no cesa de insistir. Insistir en darle voz al sujeto subalterno, insistir en tratar el tema de la memoria más allá de las fantasías

5 Esta autora, desde la perspectiva de la deconstrucción, afirma enfáticamente que el sujeto subalterno no tiene voz porque, en un mundo como el nuestro, - no hay instituciones- propias de la subalternidad que la validen. Su cuestionamiento a Foucault y Deleuze como intelectuales centrales que escriben sus presupuestos desde un punto de enunciación dominante. 
culturales es sostener una verdad. Aquello que no entra en la contabilidad del sistema asoma en el trabajo de este escritor recientemente fallecido, convertido en la exposición de una fidelidad a una verdad ontológica. Por eso mismo, decíamos antes, Gutiérrez se caracteriza por ser un escritor que en sus obras expuso fundamentalmente ideas y no solo una secuencia de opiniones ${ }^{6}$. Se nos ocurre sugerir al lector de esta nota lo dicho por Badiou acerca de ideas y opiniones en el siguiente texto de pie de página.

A modo de aclaración, cuando distinguimos ideas de las puras opiniones lo hacemos pues en la dirección de lo que conceptualiza esta dicotomía Alain Badiou.

Toda verdad, ya lo hemos dicho, se opone a las opiniones, ya que se llama opiniones a las representaciones sin verdad, los desechos anárquicos de un saber circulante [...]. Ahora bien, las opiniones son el fundamento de la sociabilidad [...] La opinión es la materia prima de toda comunicación (Badiou, 2004, p. 81).

La idea es en realidad una verdad que nos atraviesa, aunque la mayoría o la gran mayoría ni siquiera nos damos cuenta. En cambio, las opiniones son manipuladas y comprendidas por todos. La idea aparece como

6 «Llamo idea a ese intermedio entre las verdades universales, digamos eternas para provocar un poco a los contemporáneos, y el individuo. ¿Qué es entonces una vida bajo el signo de la idea en un mundo como este? Hace falta una distancia con la circulación general. Pero esa distancia no puede ser creada solo con la voluntad, hace falta que algo nos ocurra, un acontecimiento que nos lleve a tomar posición frente a lo que pasó. Puede ser un amor, un levantamiento político, una decepción, en fin, muchas cosas. Allí se pone en juego la voluntad para crear un mundo nuevo que no estará a la orden del mundo tal como es, con su ley de circulación mercantil, sino por un elemento nuevo de mi experiencia. El mundo moderno se caracteriza por la soberanía de las opiniones. Y la opinión es algo contrario a la idea. La opinión no pretende ser universal. Es mi opinión y vale tanto como la de cualquier otro. La opinión se relaciona con la distribución de objetos y la satisfacción personal. Hay un mercado de las opiniones como hay un mercado de las acciones financieras. Hay momentos en que una opinión vale más que otra, después esa opinión quiebra como un país. Estamos en el régimen general del comercio de la comunicación en el cual la idea no existe. Incluso se sospecha de la idea y se dirá que es opresiva, totalitaria, que se trata de una alienación. ¿Y por qué ocurre esto? Pues simplemente porque la idea es gratis. A diferencia de la opinión, la idea no entra en ningún mercado. Si defendemos nuestra convicción, lo hacemos con la idea de que es universal. Esa idea es entonces una propuesta compartida, no se la puede poner en venta en el mercado. Pero, como con todo lo que es gratis, la idea está bajo sospecha. Se pregunta: ¿cuál es el valor de lo que es gratis? Justamente, el valor de lo gratis es que no tiene valor en el sentido de los intercambios. Su valor es intrínseco. Y como no se puede distinguir la idea del precio del objeto, la única existencia de la idea está en una suerte de fidelidad existencial y vital a la idea. La mejor metáfora la encontramos en el amor. Si queremos profundamente a alguien, ese amor no tiene precio. Hay que aceptar el sufrimiento, las dificultades, el hecho de que siempre hay una tensión entre lo que deseamos inmediatamente y la respuesta del otro. Es preciso atravesar todo esto. Cuando estamos enamorados se trata de una idea, y eso es lo que garantiza la continuidad de ese amor. Para oponerse al mundo contemporáneo se puede actuar en política, pero no es todo: estar cautivado completamente por una obra de arte o estar profundamente enamorados es como una rebelión secreta y personal contra el mundo contemporáneo» (Alain Badiou, entrevista con Eduardo Febbro, 2012). 
resultado de una profunda meditación, sobre todo en momentos álgidos provocados por el acontecimiento, que toca al individuo llamándolo a convertirse en sujeto; es decir, comprometiéndolo a que inicie un proceso de subjetivación. En cambio, las opiniones circulan de manera cotidiana en las relaciones humanas; son sobre las que la cultura y poder dominante propician e insisten, convirtiéndolo en el único alimento de las poblaciones mayoritarias, porque nada desestabilizan, nada nuevo traen más bien van en la orientación del mantenimiento de las cosas tales como están. En la masa amorfa que constituyen las poblaciones mayoritarias hoy en día circulan a más no poder las opiniones, acicateados por la prensa, la tv y todo tipo de aparatos tecnológicos diseñados casi en su totalidad para eso; pero no solo en eso sino también en el mundo académico, en planes y programas diseñados por la hegemonía mundial (un ejemplo escandaloso son los planes y programas diseñados por el Banco Mundial para la reforma educativa en los países llamados tercermundistas). De esto, Badiou saca la conclusión de que las ideas se relacionan con la verdad y las opiniones con el saber a lo sumo. De esto se desprende, además, que la academia no produce verdades, es más bien el acontecimiento el laboratorio de producción de verdades, si de alguna manera se puede hablar de una producción de verdades. Aunque, es cierto, ningún ser humano normal escapa al mundo de opiniones, todos participamos de ella; pero algunos pueden acceder al mundo de las ideas, aunque la gran mayoría no.

III

Queda claro, entonces, lo que para nosotros significa la narrativa de Miguel Gutiérrez. De qué lado se ubica en una realidad social y cultural escindida y estrictamente jerarquizada, qué es lo que pretende por ejemplo con la elaboración de un libro múltiple en significados como lo es Poderes secretos. La narrativa de la mismidad, la narrativa del éxito y la que constituye la cultura de la queja ${ }^{7}$ definitivamente son arte de opiniones, a lo sumo son el festival de las puras opiniones. Ya ni hablar de otros rubros que en el contexto de la narrativa peruana se dan a diestra y siniestra. Por tanto, lo que propone la narrativa de Miguel Gutiérrez es fundamental para comprender sobre todo las relaciones sociales y culturales en el Perú. Sin embargo, se podría cuestionar las propuestas que vertimos en este pequeño texto; comparando la narrativa de Gutiérrez con la de otros novelistas tal vez más vendidos y reconocidos. Pero esta sería, sin duda, una comparación de narradores de éxito, aceptados por el sistema dominante

7 La cultura de la queja la define de manera clara y sorprendente S. Žižek, en su libro EI espinoso sujeto. 
mundial y tal vez hasta defensores del statu quo, escritores con una temática esencialmente de opiniones y de libros turísticos, puestos frente a un escritor como Miguel Gutiérrez cuya preocupación básica fue la exposición de ideas en el universo del mundo representado de sus obras. Desde luego, esto merecería un estudio más amplio que lamentablemente excede el marco de este trabajo.

Por supuesto, puede formularse la pregunta de si la memoria constituye una idea, una verdad. Para Giorgio Agamben ${ }^{8}$ (2006), el notable filósofo italiano que considera nuestra época como un gran campo de concentración que vive en un permanente estado de excepción, la memoria es un tema fundamental para la filosofía. Por eso es que tematiza el rol del sujeto de testimonio y si el que da el testimonio por él vivido directamente se acerca a lo realmente ocurrido. Entre otras propuestas, afirma que el pasado no simbolizado exige redención y encuentra siempre una redención. En este punto, lo que desde otra perspectiva afirma Agamben es que la memoria que queda como un resto es un segmento de lo Real que exige ser simbolizado; por tanto, quien trata de sostenerlo, como creemos que lo hace Gutiérrez en Poderes secretos básicamente, enarbola una verdad establecida en el pasado que perturba el presente y desestabiliza al futuro, siendo esta una de las características de una verdad. En otras palabras, es un tema que responde al orden ontológico y no solo a lo óntico, razón para considerar un tema como una entrada al tratamiento de una verdad. De esa verdad que nomina el pasado de las relaciones humanas como una realidad cargada de dramas que muchas veces se trató y se trata de manipular o negar, aunque no se pueda negarla u ocultarla por completo, porque siempre retorna muy a pesar de cualquier oposición.

Como se podrá apreciar, un enunciado breve propuesto por Miguel Gutiérrez entraña una posibilidad de reflexiones sobre lo que es una verdad. Nos propone, además, que el arte, en efecto, es un punto de verdad, como lo son la ciencia, la política y el evento del amor. Desde luego, una novela múltiple como Poderes secretos da para más; pero lo que particularmente nos interesa es lo que creemos la parte trascendente de la novela.

8 Giorgio Agamben es un filósofo italiano nacido en Roma en 1942, también autor de numerosas obras. Nos interesa de él su propuesta acerca del carácter político del mundo contemporáneo. Agamben considera que el mundo contemporáneo se rige con los principios de un campo de concentración y que, además, vive en un permanente estado de excepción. Libros como Homo saccer I, II y III, La comunidad que viene, El tiempo que resta, etc., son de lectura imprescindible. 


\section{Contribuciones}

Julián Pérez Huarancca ha participado en la concepción del artículo, la recolección de datos, su redacción y aprobación de la versión final.

\section{Fuente de financiamiento}

Autofinanciado.

\section{Conflicto de interés}

El autor declara no tener conflictos de interés.

\section{REFERENCIAS BIBLIOGRÁFICAS}

Agamben, G. (2006). El tiempo que resta. Madrid: Trotta.

Badiou, A. (2004). La ética. Ensayo sobre la conciencia del mal. Ciudad de México: Herder.

Gutiérrez, M. (2010). Poderes secretos. Huancayo: Bisagra.

Rancière, J. (2015). El giro ético de la estética y de la política. Santiago de Chile: LOM.

Recalcati, M. (2012). Las tres estéticas de Lacan. Buenos Aires: Ediciones del Cifrado.

Ricoeur, P. (2003). La memoria, la historia, el olvido. Madrid: Trotta.

Spivak, G. (1998). ¿Puede hablar el sujeto subalterno? Orbis Tertius, III(6), pp. 175-235.

Zizek, S. (2001). El espinoso sujeto. El centro ausente de la ontología política. Buenos Aires: Paidós. 